Ensino, Saúde e Ambiente - V7 (3), p. 13-29, Dez. 2014

\title{
PROFESSORES E O MUSEU DE BIODIVERSIDADE DO CERRADO: VÍNCULOS ATRAVÉS DA CONSTRUÇÃO COLETIVA DE RECURSOS LÚDICOS
}

\section{TEACHERS AND THE BIODIVERSITY MUSEUM: LINKAGES THROUGH THE CONSTRUCTION OF PLAYFUL EDUCATIONAL RESOURCES}

\author{
Lívia Borges dos Santos ${ }^{1}$, Daniela Franco Carvalho ${ }^{2}$ \\ ${ }^{1}$ Universidade Federal de Uberlândia/InBio, lilabs.07@ hotmail.com \\ ${ }^{2}$ Universidade Federal de Uberlândia/InBio, danielafcj@inbio.ufu.br
}

\section{RESUMO}

O setor educativo do Museu de Biodiversidade do Cerrado da Universidade Federal de Uberlândia tem uma preocupação intensa em desenvolver ações que possam possibilitar o estabelecimento de vínculos entre os professores da educação básica e o museu. Como jogos, experimentos e brinquedos podem se constituir em recursos pedagógicos interessantes no ensino de Ciências e na abordagem de temáticas ambientais foi desenvolvida uma proposta de oficinas de produção de recursos lúdicos por meio de materiais reutilizáveis. Os professores foram estimulados, através roteiros práticos, a confeccionar de forma coletiva os recursos didáticos e compartilhar suas percepções com os pares e membros da equipe técnica do museu. O presente trabalho buscou avaliar a receptividade dos professores em relação às oficinas. Do universo amostral de professores participantes, $87,9 \%$ julgaram que os recursos lúdicos serão de grande interesse e participação dos alunos na educação básica e 94,9\% informaram que os recursos são de fácil elaboração e trabalho em sala de aula, e que os utilizariam como proposta didática para abordagens diversas.

Palavras-chave: Oficinas; recursos lúdicos; ensino de Ciências, ambiente, museu

\begin{abstract}
The educational sector of the Museum of Biodiversity at Federal University of Uberlândia - Brazil has an intense concern in developing actions that may enable the establishment of linkages between the elementary school teachers and the museum. As games, toys and experiments may constitute interesting teaching resources in science education and in addressing environmental issues, a proposal was developed for a workshop production of playful educational resources by means of reusable materials. Teachers were encouraged through practical routes to fabricate collectively teaching resources and share their insights with peers and members of the technical staff of the museum. This study aimed to evaluate the receptivity of teachers in relation to the workshops. The sample universe of participating teachers, $87.9 \%$ judged that the recreational resources will be of great interest and participation of students in basic education and $94.9 \%$ reported that the resources are easy to design and work in the classroom, and that would use as a didactic proposal for different approaches.
\end{abstract}

Keywords: Workshops; recreational resources; science teaching environment, museum. 


\section{INTRODUÇÃO}

É no ensino fundamental que os alunos tomam contato pela primeira vez com certos conceitos científicos, e a aprendizagem subseqüente em Ciências depende desse primeiro contato. Se o ensino for agradável e fizer sentido para as crianças, elas gostarão de Ciências e terão maior possibilidade de serem bons alunos nos anos posteriores. Se esse ensino for aversivo exigindo memorização de conceitos fora do entendimento da criança e for descompromissado com sua realidade, a aversão pelas Ciências será instalada (Carvalho, 1997).

Para Bianconi e Caruso (2005: p.20), o ensino das ciências é muito difícil para os profissionais, principalmente devido à falta de recursos pedagógicos. Assim, aulas com metodologias não tão formais (como jogos, experimentos, brinquedos) são um ótimo recurso pedagógico para complementar o ensino das ciências, tornando-o mais prazeroso e aumentando o interesse dos alunos pelo mesmo.

Os jogos são importantes instrumentos de desenvolvimento de crianças e jovens. Não servem apenas como fonte de diversão, o que já seria importante, eles propiciam situações que podem ser exploradas de diversas maneiras (Dohme, 2008). Para Piaget (1967), o jogo favorece a construção do conhecimento. Agindo sobre os objetos, as crianças, desde pequenas, estruturam seu espaço e seu tempo, desenvolvem a noção da causalidade, chegando à representação e, finalmente, à lógica. As crianças ficam mais motivadas a usar a inteligência, pois querem jogar bem; sendo assim, esforçam-se para superar obstáculos, tanto cognitivos quanto emocionais. Estando mais motivadas durante o jogo, ficam também mais ativas mentalmente.

Como as metodologias alternativas para o ensino fundamental são essenciais para a garantia de um ensino de Ciências de qualidade, coleções novas ou reformuladas de livros didáticos tradicionais passaram a incorporar em seus textos sugestões de trabalhos em grupo, atividades lúdicas e algumas brincadeiras nos livros do $6^{\circ}$ ao $9^{\circ}$ ano (PNLD, 2011). Embora a temática ambiental permeie boa parte dessas coleções, poucas sugestões de abordagem sobre Ciências no formato de experimentos, jogos e criações diversificadas específicas sobre a questão ambiental são observadas. E ainda mais, quando são abordadas, os manuais para o professor não evidenciam de forma detalhada os procedimentos metodológicos a serem adotas pelo professor, o que fragiliza a proposição de um trabalho em sala de aula. 
A questão do lixo é dita pelos ambientalistas como um dos mais graves problemas ambientais da atualidade, a ponto de ter-se tornado objeto de proposições técnicas para seu enfrentamento algo privilegiado de programas de educação ambiental na Escola Brasileira: Pedagogia dos 3R's (Enfrentamento da questão do lixo: Reduzir, Reutilizar e Recilar). Porém, a complexidade do assunto se contrapõe com a Educação Ambiental voltada apenas para a coleta seletiva do lixo, pouco esforço é dedicado à análise do significado da reciclagem, tomando-a apenas como uma atividade-fim, não vivenciada pelos alunos (Loureiro et al., 2002).

A interação de educação com a reciclagem é muito importante, pois sensibiliza as diferentes gerações sobre a realidade com mudanças de atitudes. Projetos práticos como o "Reciclar Brincando" da UNIVAP, desenvolvido com alunos do ensino infantil e fundamental de escolas localizadas em Santa Branca - SP mostram que a Educação Ambiental pode ocorrer através de práticas recreativas aplicadas em atividades temáticas, sobre reciclagem e lixo, na metodologia do "aprender brincando". As atividades lúdicas podem preparar um cidadão preocupado em ajudar a melhorar a qualidade de vida ambiental, não só pelos seus atos a serem praticados, mas também pela disseminação "boca-a-boca" do conhecimento (Nogueira et al., 2008).

Tendo em vista os desafios impostos à escola frente às questões ambientais, especificamente sobre os resíduos sólidos recicláveis, em 2010, pela Universidade Federal de Uberlândia, ingressantes do curso de Ciências Biológicas realizaram uma mostra de conteúdos biológicos em uma escola municipal. Dentre várias ações realizadas, houve a atividade que envolvia conceitos relativos aos resíduos sólidos e possibilidades de reuso de embalagens, por meio de uma simulação de pescaria, onde os estudantes utilizavam varas de pesca para fisgar resíduos em uma piscina com água. Os brindes eram brinquedos como vai-e-vem, peteca, carrinhos, bonecas, animais... Todos esses confeccionados com material reciclável como garrafas pet, papelão, caixas de ovos e latas. Buscou-se discutir com os alunos a possibilidade de reaproveitamento de materiais e a importância do descarte correto dos resíduos sólidos, com fundamentos teóricos da educação ambiental.

A qualidade e criatividade dos brinquedos produzidos chamaram a atenção das professoras e direção da escola, que solicitaram novas edições da mostra e a oferta de oficinas de confecção dos brinquedos, para posterior utilização em sala de aula com estudantes do ensino fundamental. Essa solicitação nos incentivou a elaborar um projeto, dada à importância de se trabalhar com material didático alternativo na escola, 
no contexto do reuso e do reaproveitamento de embalagens recicláveis, e a dificuldade do professor, principalmente do ensino infantil e fundamental, de abordar a temática ambiental em sala de aula ressaltando o aspecto lúdico.

Como compartilhamos das observações de Dohme (2008) de que o local onde a atividade lúdica será desenvolvida deve ser levado em consideração, pois irá influenciar na formulação do seu objetivo, na condução e no interesse que irá despertar, fizemos os seguintes apontamentos iniciais para delimitar o escopo do trabalho: a) os professores da rede estadual, municipal e particular de Uberlândia - MG têm limitações para abordar a temática ambiental em sala de aula, dada as limitações dos livros didáticos e da estrutura das escolas; b) os professores têm dificuldades para freqüentar ativamente parques ou museus com seus alunos, devido a questões logísticas, ausência de tempo e falta de integração com a equipe técnica dos espaços não formais de Educação; c) os professores não encontram facilmente sugestões de atividades lúdicas sobre a temática ambiental, pois não há revistas especializadas nesse sentido, voltadas ao docente da educação básica; d) os professores do ensino fundamental geralmente agendam uma visita guiada no Museu de Biodiversidade do Cerrado ${ }^{1}$ quando deseja abordar a temática ambiental com seus alunos, dado ao acervo do museu ser constituído pela fauna e flora do Cerrado e haver possibilidade de realização de trilhas em trechos de mata nativa.

Nesse sentido, nos propusemos a integrar práticas por meio de oficinas de produção de recursos didáticos lúdicos para a abordagem de temáticas ambientais tanto no espaço da escola como no Museu de Biodiversidade do Cerrado, estabelecendo assim vínculos entre as escolas e o museu, como espaços constitutivos de formação e aperfeiçoamento dos professores. A produção coletiva de recursos didáticos lúdicos com resíduos sólidos recicláveis foi o alinhavo desses vínculos.

\section{DESENVOLVIMENTO}

Inicialmente foram elaborados modelos didáticos de animais (peixes e insetos) e plantas do Cerrado utilizando materiais recicláveis (Figura 1). Os modelos elaborados foram: Piau (Leporinus piau), utilizando tela gradeada, jornal, sacola plástica e cola; Borboleta - (Agraulis vanillae), utilizando papel machê, papelão, arame e cola quente e;

\footnotetext{
${ }^{1}$ Órgão complementar do Instituto de Biologia da Universidade Federal de Uberlândia, localizado no Parque Municipal Victório Siquierolli. Para maiores informações sobre o Museu de Biodiversidade do Cerrado, acesse www.mbc.ib.ufu.br.
} 
Ipê-amarelo - (Tabebuia chrysotricha) utilizando tela gradeada, jornal, cola, fita adesiva, sacola plástica, anzol, garrafinha de plástico, papel. O tempo de elaboração variou entre os modelos devido aos diferentes níveis de dificuldade e formas de desenvolvimento.
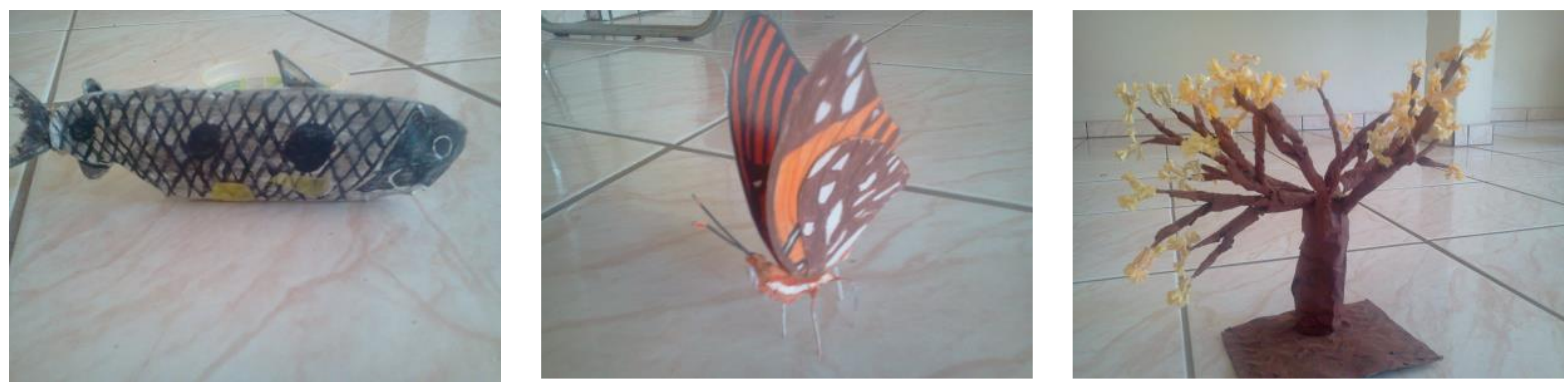

Figura 1: Modelos didáticos de animais e plantas do Cerrado elaborados.

Fonte: própria.

Após a elaboração dos modelos, para a execução das oficinas com materiais reciclados o Centro Municipal de Estudos e Projetos Educacionais Julieta Diniz (CEMEPE) foi contatado a fim de que a parceria fosse estabelecida para realização das atividades durante os dias de Módulo dos professores da educação básica pública do município de Uberlândia - MG, nos quais os professores são liberados para capacitação. Após a parceria ter sido firmada, os professores foram informados sobre as oficinas e realizaram inscrição nas mesmas.

As oficinas foram realizadas partindo-se de uma breve apresentação da proposta através de imagens e fornecimento do termo de consentimento livre e esclarecido aos participantes com um resumo da pesquisa e autorização para coleta dos dados através de um questionário. Os materiais recicláveis utilizados nas oficinas foram disponibilizados pela equipe técnica proponente e parte foi cedida pelos participantes.

Dois formatos de oficinas foram desenvolvidas e ofertadas no total de cinco encontros com os professores: a) Resgatando a ludicidade através da construção de brinquedos com materiais recicláveis - para professoras do primeiro ano do ensino fundamental com duração de quatro horas.

Foram levados recursos lúdicos (brinquedos) com seus respectivos roteiros (Figura 2) e sugestões de situações em que poderiam ser utilizados: Quebra cabeça de palito, Caixa de música, Pé de lata, Lápis piorra, Sapo bilboquê; b) Criação de brinquedos a partir de material reciclável - para professoras do quinto ano do ensino 
fundamental com duração de duas horas e para professoras de Ciências do $6^{\circ}$ ao $9^{\circ}$ ano, com duração de quatro horas. Foram trabalhados três brinquedos: Pincel de bolinha de sabão, Bolinha voadora e Ioiô de papel com os roteiros (Figura 3).

ENCONTRO DE FORMAÇÃO CONTINUADA COM PROFESSORES DO $1^{\circ}$ ANO EF - 05-11-12

\section{Quebra Cabeca de Palito:}

1. Colocar 10 palitos em fileira, tal como o

desenho;

2. Prendê-los com uma fita;

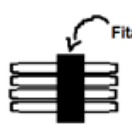

3. Virar, e fazer o desenho (ou colagem, pintura...) do lado oposto à fita;

4. Em um apoio de papelão, colar 4 palitos, formando a moldura do quebra cabeça (de modo que o quebra cabeça caiba dentro);

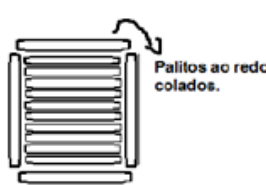

Qbs: Coloque os 10 palitos que estão com a fita dentro da moldura, antes de colar os palitos, para certificar que irá caber na moldura.

ATENÇÃO: cole APENAS os palitos da moldura.

5. Após seco, tirar o excesso de papelão, deixando apenas o tamanho da moldura.

6. Tirar a fita dos palitos, e misturar ENCONTRO DE FORMACÄO CONTINUADA COM PROFESSORES DO 1ㅇ ANO EF - 05-11-12

Lápis Piorra:

1. Fazer o "canudinholápis": Cortar fol ha de revista ao meio, e utilizando uma metade, usar lápis para enrolar a revista. Começar enrolando, como está indicado no desenho.

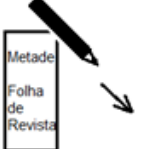
Corolar um pouco, e passar um pouco de cola na revista, fazer o mesmo no final. Conforme for enrol ando, ir puxando o lápis no sentid indicado pela seta. O canudo estará pronto, formando um tubinho. Comprimir/amassar o tubo. Fazer o mesmo com 5 fol has (10 metades). Enrolar um tubinho num lápis. No começo, passar cola no canudinho amassado (não no lápis), e enquanto estiver enrolando também. Conforme for enrolando e, formará um "caracol", o lápis do centro poderá ser retirado. No final, deixar uma ponta, para colar outro Canudinho amassado e continuar fazendo o caracol grande.

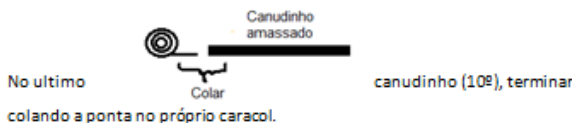

2. Colocar o "caracol" pronto nolápis, e fazer um caracol menor (Mesmo procedimento do Canudinho lápis, porém com 3 fol has (6 metades).

3. Colocar o caracol menor, embaixo do maior, no lápis também.
ENCONTRO DE FORMAÇÃO CONTINUADA COM PROFESSORES

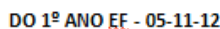

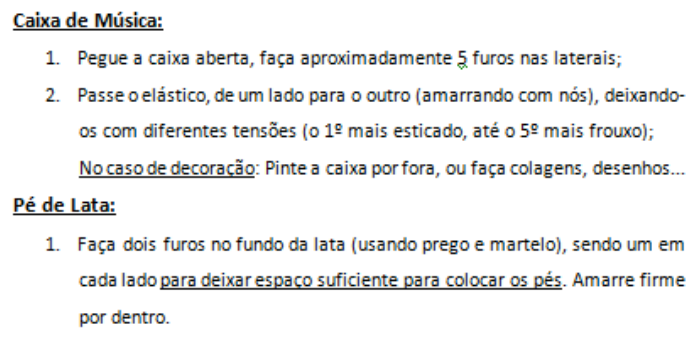

1. Pegue a caixa aberta, faça aproximadamente 5 furos nas laterais;

2. Passe o elástico, de um lado para o outro (amarrando com nós), deixandoos com diferentes tensões (o 19 mais esticado, até $05^{\circ}$ mais frouxo); No caso de decoracão: Pinte a caixa por fora, ou faça colagens, desenhos... Pé de Lata:

1. Faça dois furos no fundo da lata (usando prego e martelo), sendo um em cada lado para deixar espaco suficiente para colocar os pés. Amarre firme por dentro.

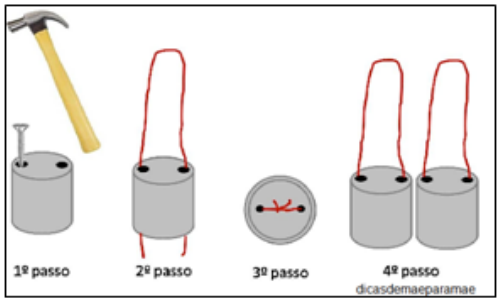

ENCONTRO DE FORMAÇÃO CONTINUADA COM PROFESSORES DO 1ำ ANO EF - 05-11-12

Sapo bilboquê:

1. Desmonte a caixa;

2. Nos cantos, aproveitando a dobra da caixa, cortar um pedaço que caiba a mão;

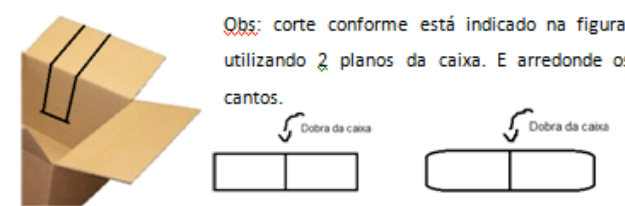

3. Caso a caixa não seja branca, decorar e esperar secar:
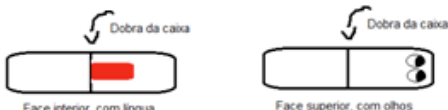

Dica: pinte deverde, faça ol hinhos (na face superior), e lingua (na face interna).

4. Fazer um rolinho de papel de revista (passo 1 do Lápis Piorra: usando apenas 1 metade), passar o barbante dentro, amarrar;

5. No barbante, grampear a extremidade (oposta a que esta amarrada no rolinho) na face inferior, abaixo da língua, na borda.

6. Colocar o Gominha na dobra da caixa (se ficar largo na mão, dar duas voltas).

Figura 2: Roteiro das oficinas Resgatando a ludicidade através da construção de brinquedos com materiais recicláveis.

Fonte: própria. 
Ensino, Saúde e Ambiente - V7 (3), p. 13-29, Dez. 2014

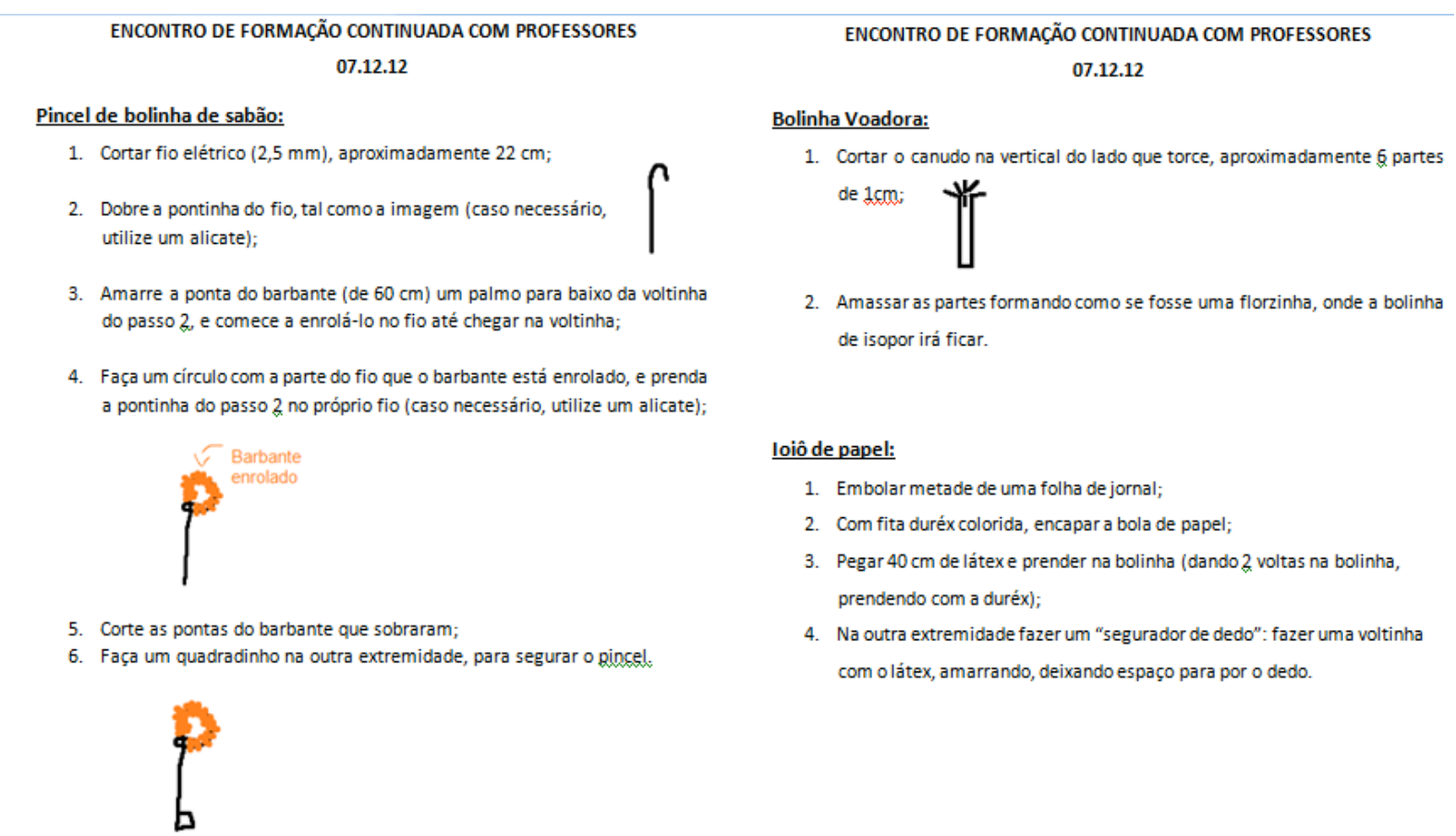

Figura 3. Roteiro das oficinas Criação de brinquedos a partir de material reciclável.

Fonte: própria.

Em todas as oficinas as professoras foram estimuladas a se orientarem pelos roteiros, para que em situações futuras em que fossem trabalhá-los as mesmas possuíssem a habilidade de elaborar os brinquedos de forma autônoma, apenas com o apoio do roteiro. A seleção dos brinquedos que foram abordados nas oficinas ocorreu levando-se em consideração a dificuldade de execução, para que as professoras pudessem partir do recurso lúdico mais simples de ser construído e, futuramente, atuarem na elaboração dos modelos de animais e plantas do Cerrado disponibilizados como exemplos.

Ao final de todas as oficinas, foram aplicados questionários com perguntas fechadas e abertas (André e Lüdke, 1986) às professoras que se dispuseram voluntariamente e anonimamente a colaborar com a pesquisa. $\mathrm{O}$ questionário foi composto por seis questões com três alternativas cada, relativas às atividades das oficinas. No total foram cinquenta e oito (58) questionários respondidos, sendo trinta e sete (37) por professoras do $1^{\circ}$ ano, onze (11) por professoras do $5^{\circ}$ ano e dez (10) por professoras do $4^{\mathrm{o}}$ ano. 


\section{RESULTADOS E DISCUSSÕES}

Na primeira questão, as professoras foram indagadas sobre a disponibilidade dos recursos pedagógicos na escola de educação básica, e os resultados podem ser observados na Figura 4, que segue.

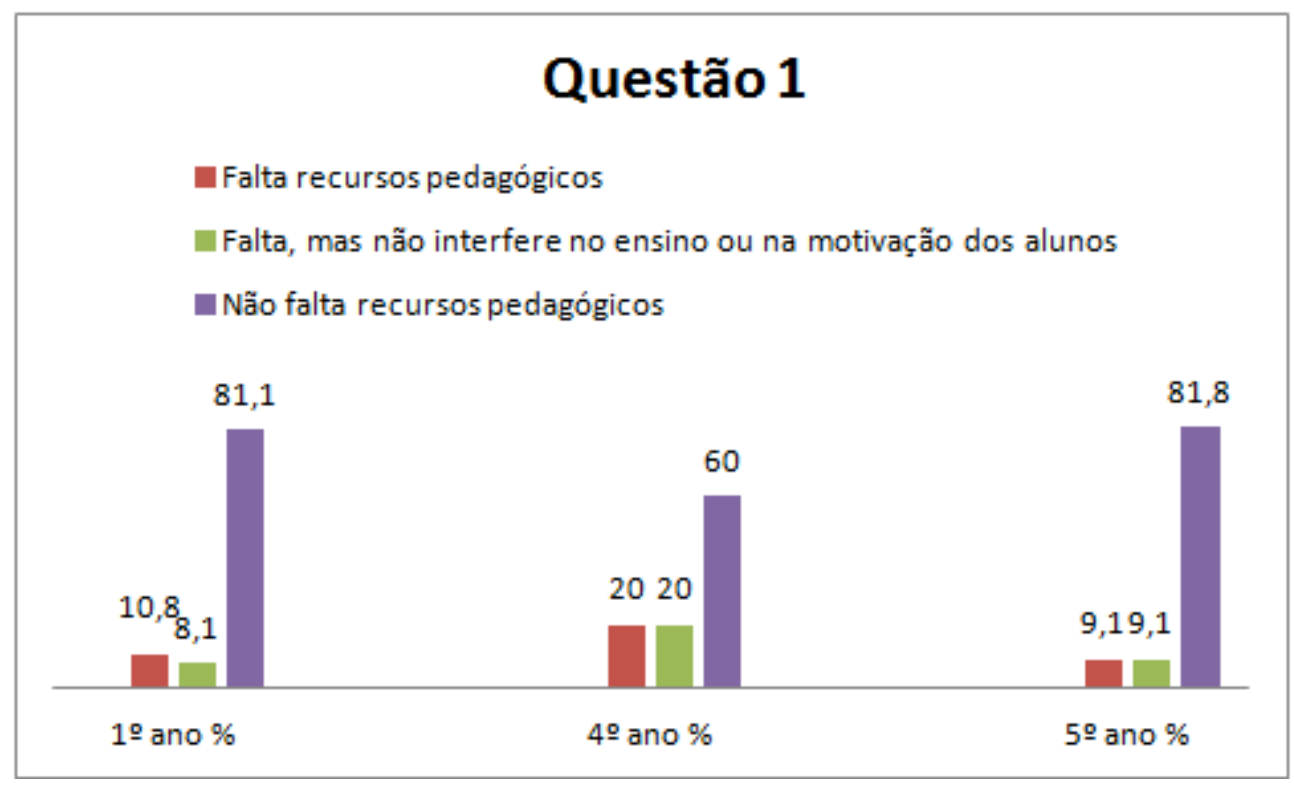

Figura 4. Resultados referentes sobre a disponibilidade dos recursos pedagógicos na escola de educação básica.

Fonte: própria.

Dentre as professoras, $12 \%$ (7) consideraram que faltam recursos pedagógicos, confirmando estudos que apoiam a dificuldade dos professores nesse sentido e propõe aulas com metodologias diferenciadas para deixar este ensino mais prazeroso e interessante (Bianconi e Caruso, 2005). Diante da dificuldade no entendimento de conceitos científicos pelos alunos, a inexistência de recursos didáticos eficazes nas escolas e a grande frequência de aulas expositivas, as atividades ligadas à prática de experiências, simulações (jogos), demonstrações e excursões em ambientes naturais são modalidades que proporcionam aos alunos uma vivencia com métodos científicos e os relacionem com as implicações ambientais aprendendo de forma significativa alguns conceitos básicos acerca do reino vegetal e meio ambiente (Oliveira e Paes, 2009).

Das professoras, $10 \%$ (6) julgaram que falta, mas que esse fato não interfere no ensino ou na motivação dos alunos. Esses dados reforçam estudos que indicam que cabe ao professor decidir quais materiais são necessários para que o aluno aprenda de forma 
mais efetiva e dinâmica (Souza,2007). A curiosidade é um elemento fundamental do processo de ensino-aprendizagem, ao ser despertada ela contribui para a motivação dos alunos na busca dos conhecimentos. Em vista que muitos recursos facilitadores do ensino-aprendizagem faltam à escola, mas que, apesar desta falta, as condições motivadoras na sala de aula dependem menos disto, e mais da contribuição do professor para despertar o interesse dos alunos, já que, além do valor motivador que o conteúdo em si pode e deve ter, o contexto de ensino-aprendizagem é influenciado por muitos fatores. Dentre eles, se destacam fatores afetivos vigentes na relação professor-aluno, tais como: a disponibilidade do professor para o aluno; o respeito e afeto presentes na relação, bem como, a capacidade do docente de ser acolhedor e positivo. O papel do professor em sala como instrumento motivacional deve ele ressaltar a importância da disciplina na formação acadêmica, bem como na sua vida profissional estimulando o aprendizado diante de suas futuras perspectivas de vida (Filho, 2009). O mesmo foi destacado por Almeida (1998) que afirma que o bom êxito da atividade lúdicopedagógica depende do bom preparo do professor para essa ação.

Nos questionários, 78\% (45) das professoras julgaram que não faltam recursos pedagógicos, confirmando estudos que discorrem que as instituições escolares devem disponibilizar os recursos que serão necessários para o uso do professor, e que estes devem utilizar os recursos didáticos como auxilio para que no futuro seus alunos aprofundem e ampliem seus conhecimentos e produzam outros conhecimentos a partir desses. Para Souza (2007), o material a ser utilizado deverá proporcionar ao aluno o estimulo à pesquisa e a busca de novos conhecimentos, o propósito do uso de materiais concretos no ensino escolar é o de fazer o aluno a adquirir a cultura investigativa o que o preparará para enfrentar o mundo com ações práticas sabendo - se sujeito ativo na sociedade. Nesse mesmo sentido, Viscovini e colaboradores (2009) afirmam que diante das mudanças que as escolas atualmente passam (expansão da escolaridade a todos os segmentos da sociedade, provocando o embate teórico entre currículo, formação docente e a realidade pedagógica vivenciada nas escolas), a utilização de técnicas diversas e materiais de apoio pedagógico com o intuito de respaldar o professor com habilidades instrumentais tais como os experimentos de ensino e o uso de recursos tecnológicos. Assim, se faz frequente a preocupação em formar e atualizar o professor frente às necessidades técnicas colocadas por novas demandas de conteúdo. 
$\mathrm{Na}$ segunda questão, foi perguntado às professoras sobre a utilização dos recursos lúdicos no ensino, como uma alternativa à falta de outros materiais, e os dados estão apresentados na Figura 5.

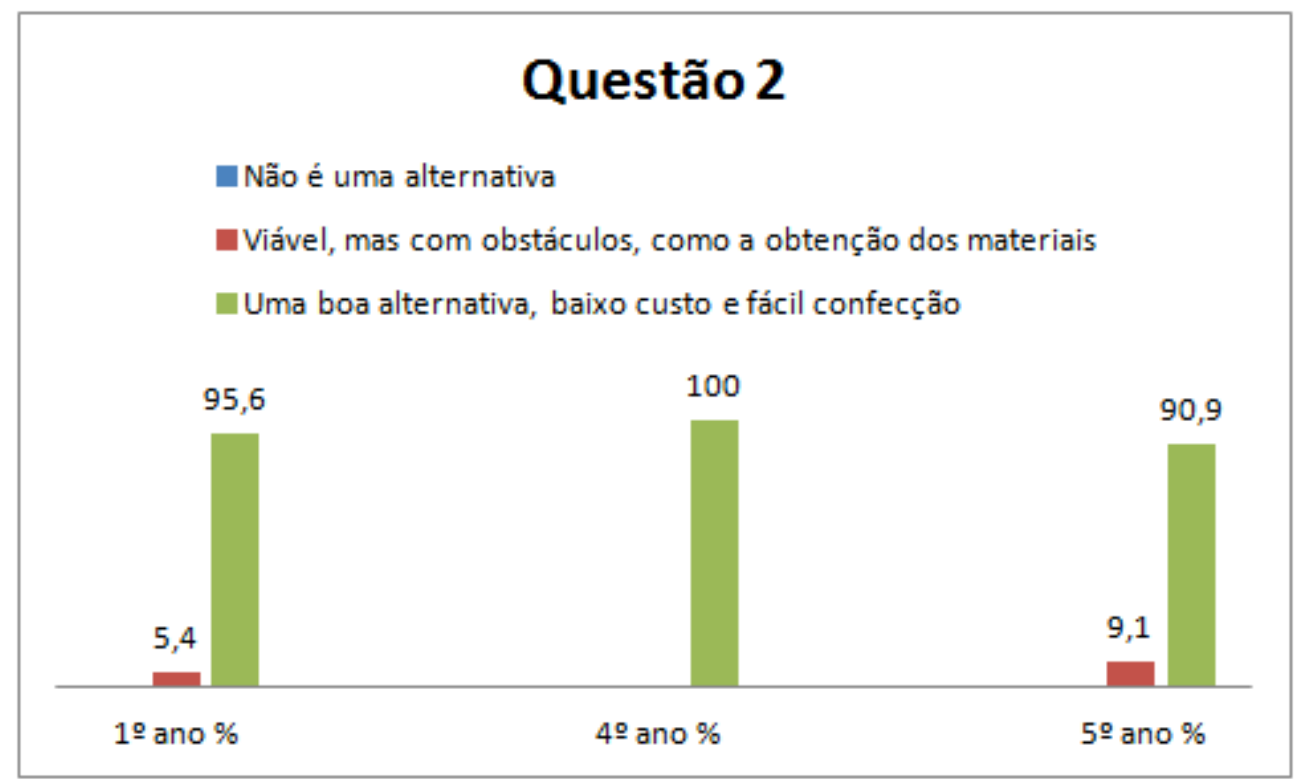

Figura 5. Resultados referentes à utilização dos recursos lúdicos no ensino. Fonte: própria.

Nenhuma das professoras considerou que o uso de recursos lúdicos não seria uma alternativa, assim todas consideram o uso viável, apoiando trabalhos que evidenciam que o lúdico é uma estratégia de estímulo na construção do conhecimento humano e na progressão das diferentes habilidades operatórias, além de se constituir como uma importante ferramenta de progresso pessoal e de alcance de objetivos institucionais. Santos e Jesus (2010) afirmam que é grande a responsabilidade do educador para estimular a aprendizagem dos educandos fazendo-se a integração dos conteúdos curriculares propostos com o lúdico (jogos, brinquedos e brincadeiras). Para Dohme (2008), as atividades lúdicas são uma prática privilegiada, mais do que aceitas como rotina da educação de crianças do ensino fundamental, para a aplicação de um ensino que visa o desenvolvimento pessoal e a atuação cooperativa na sociedade.

A grande maioria das professoras, 94,9\% (55), julgaram ser uma boa alternativa, de baixo custo e fácil confecção, relacionando a utilização de materiais alternativos de baixo custo (como os descartáveis) à valorização da prática da reutilização dos materiais, o que pode promover o desenvolvimento de uma postura mobilizadora. Para Pasquali e colaboradores (2006), os materiais alternativos não precisam de local 
específico, podem ser utilizados na sala de aula, podendo ser adotados por qualquer escola independente do nível sócio-econômico.

Das professoras, $5,1 \%$ (3) afirmaram que é viável a utilização, mas com obstáculos, como a obtenção dos materiais. Para Felix (2007) a proposta da coleta seletiva de resíduos no ambiente escolar é uma ação educativa que visa investir numa mudança de mentalidade como um elo para trabalhar a transformação ambiental, e nesse sentido, nossa pesquisa aponta que a confecção de recursos lúdicos a partir dessa ação poderia minimizar as dificuldades apontadas pelas professoras.

A Figura 6 apresenta as respostas referentes à questão 3, na qual as professoras foram indagadas sobre os roteiros de confecção dos recursos lúdicos tratados na oficina.

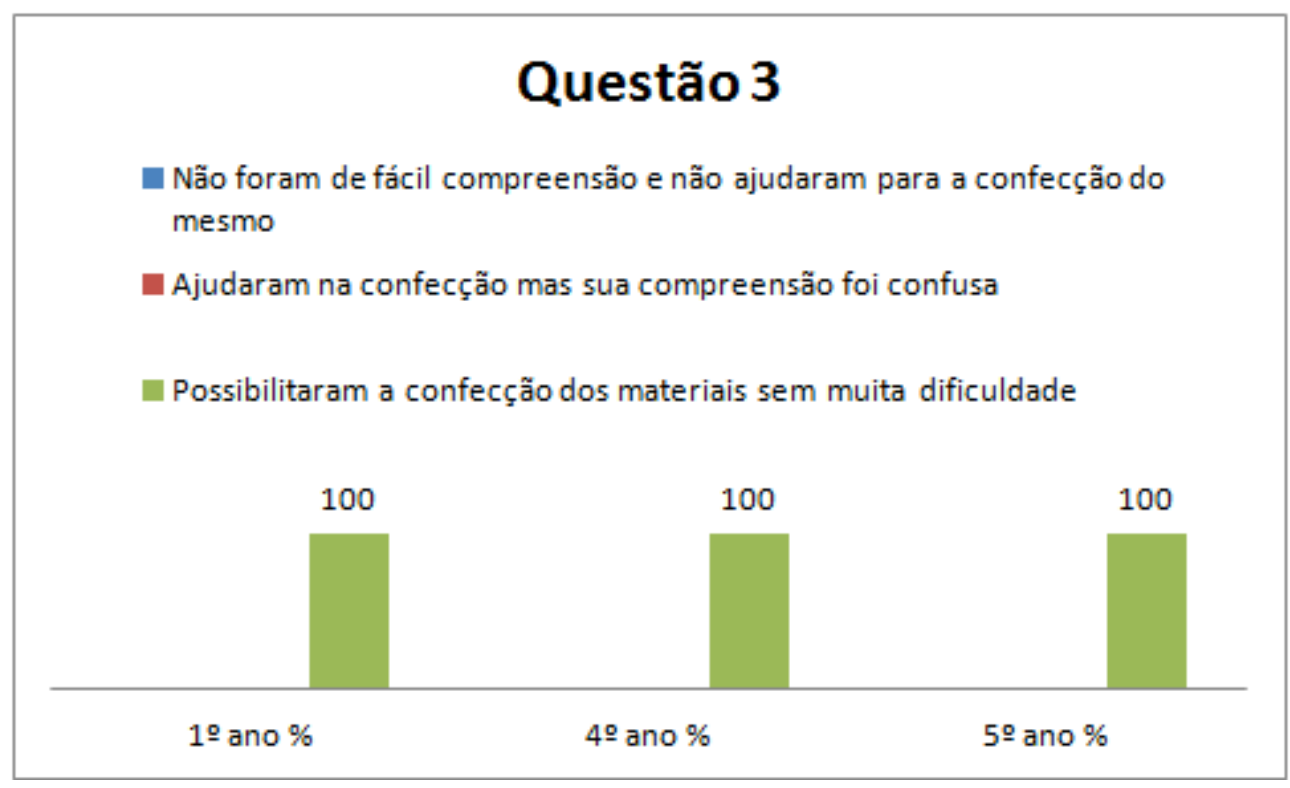

Figura 6. Resultados referentes aos roteiros de confecção dos recursos lúdicos tratados na oficina. Fonte: própria.

Nenhuma professora julgou que os roteiros não foram de fácil compreensão e não ajudaram para a confecção dos materiais, ou foram de compreensão confusa. Todas as professoras (58) afirmaram que os roteiros possibilitaram a confecção dos materiais sem muita dificuldade, apoiando estudos que reforçam a importância de guias para os professores. Embora saibamos que é fundamental para os professores o desenvolvimento de ações pedagógicas de forma autônoma, Passos e colaboradores (1994) chamam a atenção de que os Guias de Orientação Didática podem ser os 
elementos para a construção de projetos coletivos de pesquisas e debates, com o objetivo de levar os professores à aquisição, pelo uso, das vivências necessárias à orientação de sua prática pedagógica. Santos (2010) reforça a necessidade de montagem de guias lúdicos ilustrados para introdução do ensino Ciências nas séries iniciais do Ensino Fundamental devido à carência de materiais que auxiliam o professor para introduzirem a disciplina, o que acarreta em uma boa parte dos alunos que entra no Ensino Médio traz consigo uma ideia de Ciências rotulada como "difícil e complicada".

A quarta questão foi elaborada sobre os recursos lúdicos tratados na oficina, levando-se em consideração a dificuldade de confecção por parte dos professores, e os resultados estão apresentados na Figura 7.

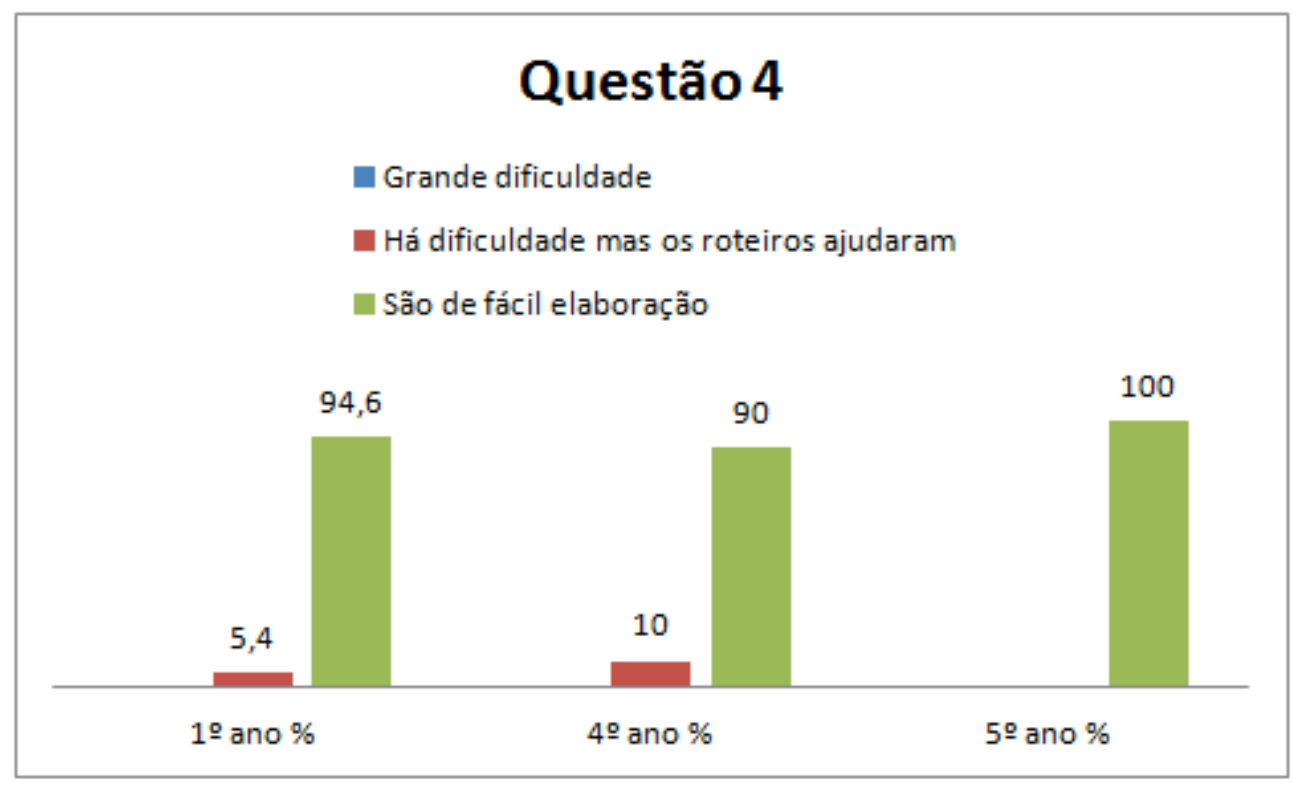

Figura 7. Resultados referentes à dificuldade de confecção dos recursos lúdicos tratados na oficina. Fonte: própria.

Nenhuma das professoras julgou que os materiais elaborados nas oficinas foram de grande dificuldade. Somente $5,1 \%$ (3) das professoras mencionaram que há dificuldade, mas que os roteiros as ajudaram na confecção. E a maioria 94,9\% (55) das professoras julgou que os roteiros proporcionam uma fácil elaboração. Dessa forma, compreendemos que as oficinas se mostraram um espaço de socialização de experiências e que o roteiro foi importante para a confecção dos recursos lúdicos, uma vez que houve muita troca de informação e de experiências entre as professores durante o exercício de confecção. Nesse sentido, não somente o roteiro, mas a oficina em si, se 
tornou fundamental para que as professoras desenvolvessem os recursos e discutissem sobre o processo de confecção. Nessa vertente, Candau (1999) entende oficina pedagógica como metodologia educacional caracterizada pela "construção coletiva de um saber, de análise da realidade, de confrontação e intercâmbio de experiências". Para Almeida e colaboradores (2004) as oficinas são uma alternativa de prática pedagógica da educação ambiental onde educadores e educandos atuam juntos na construção coletiva e reflexiva do conhecimento em um espaço de vivências, de reflexão, de aprendizado e de sistematização do saber. De acordo com Freire (2002), os processos educativos devem ser dinâmicos e precisam estimular a criatividade, e assim, entendemos a oficina como um espaço que oportunizou essa dinamicidade.

$\mathrm{Na}$ quinta questão, foi perguntado às professoras sobre os recursos lúdicos tratados na oficina, levando-se em conta o possível interesse dos alunos. As respostas a essa questão estão informadas na Figura 8.

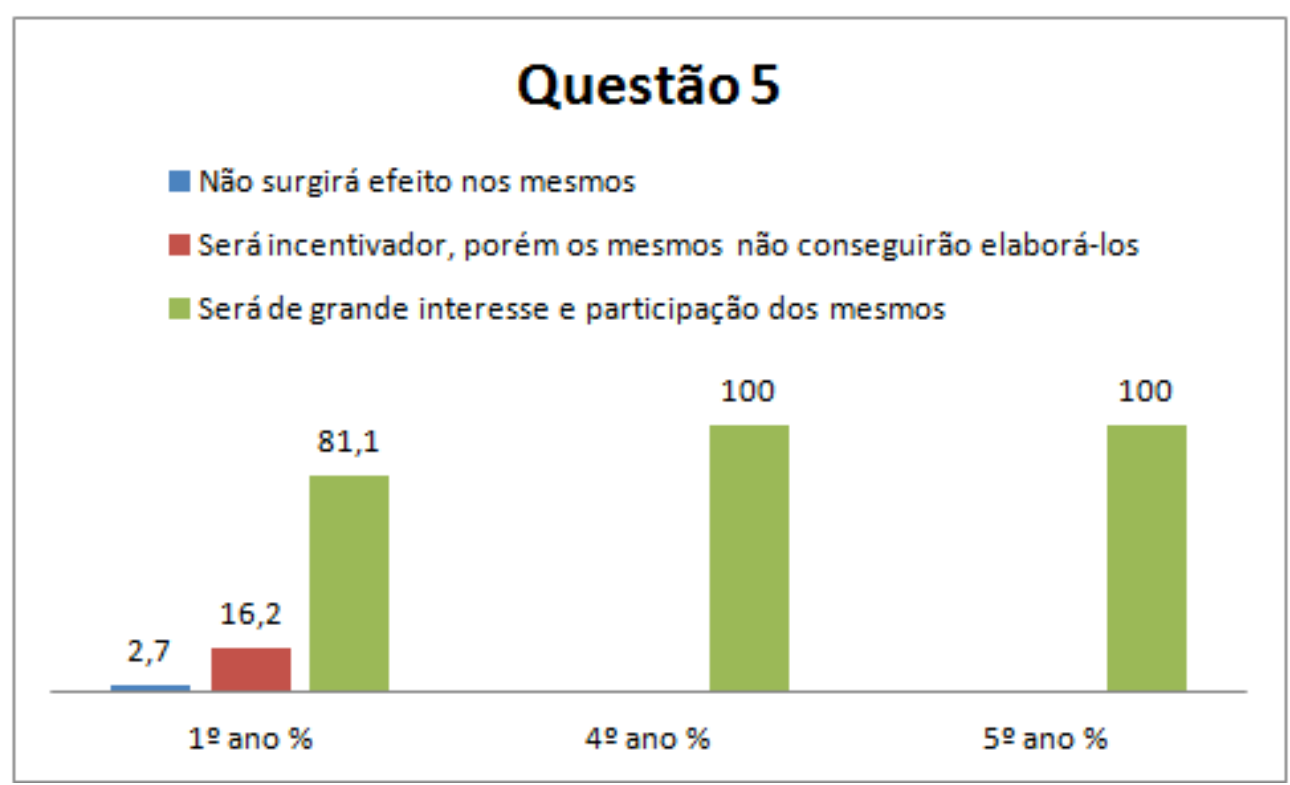

Figura 8. Resultados referentes aos recursos lúdicos levando-se em conta o possível interesse dos alunos. Fonte: própria.

Dentre as professoras participantes, apenas uma professora julgou que os recursos lúdicos trabalhados na oficina não terão efeito sobre os alunos. Seis professoras $(10,4 \%)$ afirmaram que será incentivador, porém os alunos não conseguirão elaborá-los. Das participantes, 87,9\% (51) julgaram que será de grande interesse e provavelmente haverá participação dos mesmos. De acordo com Amaral (2010), ao promover como 
metodologia alternativa a construção de modelos didáticos pelos próprios estudantes desenvolve-se o trabalho coletivo, aguça a criatividade do educandos, torna o aluno ativo na construção de seu próprio conhecimento e faz do processo ensino aprendizagem algo mais interessante.

Essa é nossa compreensão ao propor o trabalho com a oficina e a elaboração dos recursos lúdicos pelos professores. De que o trabalho coletivo, seja entre os professores, seja na escola com os alunos, é espaço de formação importante que promove a socialização de ideias e experiências no momento da confecção dos recursos.

A sexta questão tratou sobre os recursos lúdicos elaborados na oficina e sua provável utilização em sala de aula com os alunos. Os resultados estão expressos na Figura 9.

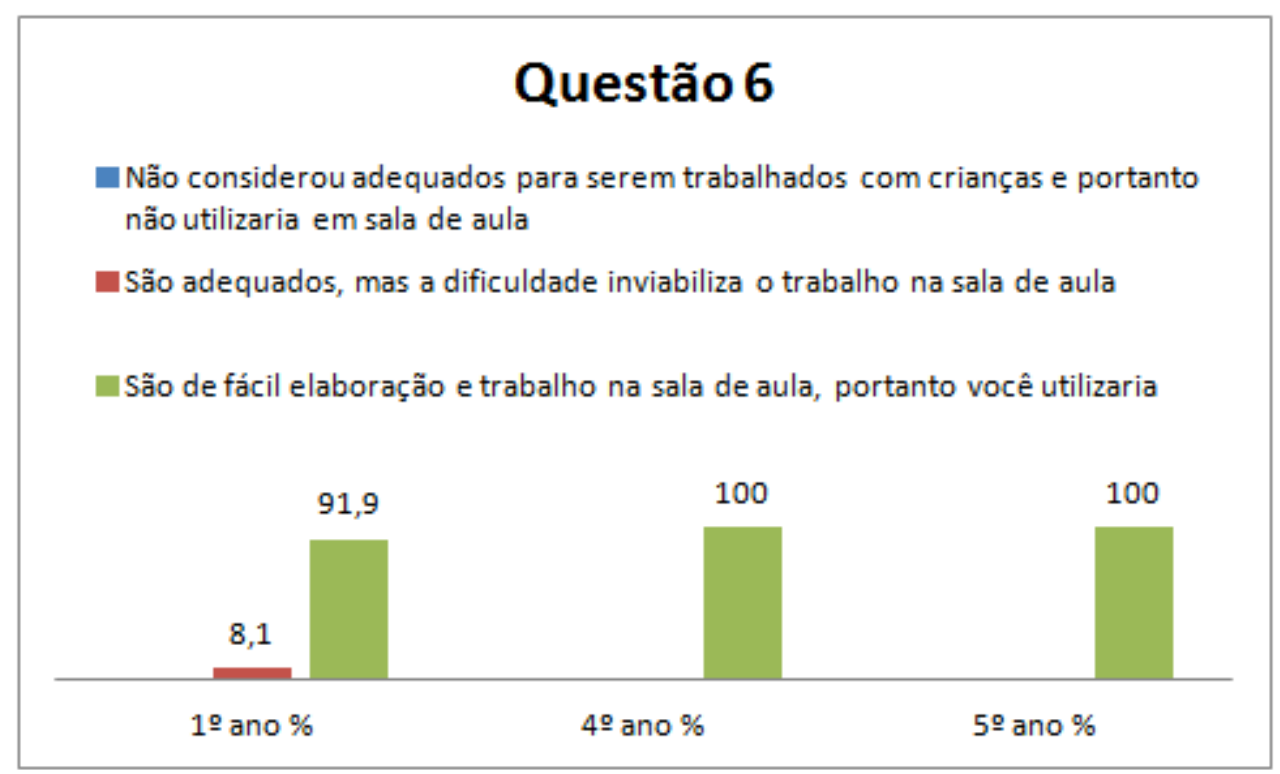

Figura 9. Resultados referentes à provável utilização dos recursos lúdicos em sala de aula. Fonte: própria.

Nenhuma das professoras julgou que os recursos lúdicos confeccionados na oficina não são adequados para serem trabalhados com crianças e, portanto não utilizaria em sala de aula. Três professoras $(5,1 \%)$ do $1^{\circ}$ ano julgaram que são adequados, mas a dificuldade de elaboração inviabiliza o trabalho na sala de aula com os alunos da faixa etária que elas atuam. Já 94,9\% (55) das professoras afirmaram que os recursos são de fácil elaboração e trabalho na sala de aula, portanto, utilizariam. Dessa forma, acreditamos que a oficina colaborou para a percepção por parte dos 
professores que a elaboração dos recursos lúdicos é viável para o trabalho em sala de aula, com os alunos. Acreditamos que mais do que a confecção em si dos recursos, a oficina é um espaço de interação promotor da relação professor-aluno. Nesse sentido, Cruz e colaboradores (2011), afirmam que a oficina pedagógica constitui-se em um dispositivo importante na educação, visto que permite a dinamização do processo de ensino-aprendizagem, e ainda é uma metodologia muito flexível, que se adapta a realidade de cada escola. Para Colomina e colaboradores (2004), a cooperação entre educadores e educando durante a realização de uma oficina pedagógica diminui a distância entre ambos e por isso facilita o processo de ensino-aprendizagem. Ribeiro (2006) percebe que durante a ação em uma oficina, o professor passa a atuar como um mediador do processo de ensino-aprendizagem, deixando de ser o detentor do conhecimento e agindo de forma inovadora auxiliando os estudantes na construção de novos saberes.

Um outro dispositivo que pode ser evidenciado com a oficina é a potencialidade de abordagem lúdica de elementos do Bioma Cerrado, e a discussão de temas relacionados em sala de aula, a partir de materiais recicláveis, disponibilizados com os roteiros de confecção. A associação da oficina com o ambiente do Museu de Biodiversidade do Cerrado, é ainda mais interessante, no sentido de pensar propostas em parceria entre o setor educativo do museu e professores da educação básica, que possam articular significados à visita guiada e expandir os conhecimentos vivenciados no museu de forma perpetuada na escola, tendo a confecção dos recursos lúdicos como uma alternativa de entremear os saberes científicos com as emoções do público escolar.

\section{CONCLUSÃO}

De acordo com os resultados obtidos na proposta pedagógica de utilização dos recursos lúdicos com materiais recicláveis em sala de aula para deixar o ensino de ciências prazeroso e interessante para o aluno, em que 87,9\% (51) das professoras julgaram que serão de grande interesse e participação dos alunos. Da mesma forma, 94,9\% (55) das professoras julgaram que os recursos lúdicos abordados são de fácil elaboração e trabalho na sala de aula, portanto os utilizariam em sala. Assim, esta proposta perfaz a tendência atual que se instaura no ensino, pois se utiliza de uma metodologia diferenciada com a valorização da participação dos alunos e ação pró-ativa dos professores. 
Como em todas as oficinas houve participação das professoras e sugestões para que a iniciativa se estenda às escolas, percebemos que as oficinas pedagógicas são instrumentos importantes para a abordagem de métodos alternativos para o ensino de Ciências na temática ambiental.

A aproximação das professoras com a equipe técnica do Museu de Biodiversidade do Cerrado reforça a necessidade de trabalhos integrados que possam garantir uma unidade da relação museu-escola, para que ações coletivas possam incentivar a visitação ao museu e a perpetuação de atividades na escola.

\section{REFERÊNCIAS BIBLIOGRÁFICAS}

ALMEIDA, L. F. R.; BICUDO, L.R.M.; BORGES, G. L. A.. Educação ambiental em praças públicas: professores e alunos descobrindo o ambiente urbano. Rev. Ciênc. Ext, v. 1 (1), p. 91, 2004.

ALMEIDA, P. N. Educação lúdica. São Paulo: Loyola, 1998.

AMARAL, J.A.; BEZERRA, C.S.; CARMO, F.N.A.; ALVES, N.T.O.; MOURA, D.S.; FERREIRA, E.R.G.; PEREIRA, C.I.V. Construção e Avaliação de modelos didáticos destinados ao ensinoaprendizagemde Biologia. Sistema de Gerenciamento de Conferências (OCS), V CONNEPI. Disponível em:

<http://connepi.ifal.edu.br/ocs/index.php/connepi/CONNEPI2010/paper/viewFile/1166/ 678> Acessado em: 16 de fevereiro de 2013.

BIANCONI, M.L.; CARUSO, F. Educação não formal. Ciência e Cultura, São Paulo, v. 57 (4),p. 1-3, 2005.

CANDAU, V.M., ZENAIDE, M.N.T. Oficinas Aprendendo e Ensinando Direitos Humanos, João Pessoa: Programa Nacional de Direitos Humanos; Secretaria da Segurança Pública do estado da Paraíba; Conselho Estadual da Defesa dos Direitos do Homem e do Cidadão. 1999.

CARVALHO, A. M. P. Ciências no ensino fundamental. Faculdade de Educação da USP, v.101, p. 152-168, 1997.

COLOMINA, R., ONRUBIA, J.; ROCHERA, M. Interactividade, mecanismos de influência educacional e construção do conhecimento na sala de aula. In

Desenvolvimento psicológico e educação, p. 294-308, 2004.

CRUZ, V. R. M.; ANTUNES, A. M.; FARIA, J. C. N. M. Oficina de produção de materiais pedagógicos e lúdicos com reutilizáveis: uma proposta de educação ambiental no ensino de ciências e biologia. Enciclopédia Biosfera, Centro Científico Conhecer Goiânia,v. 7, (12), 2011.

DOHME, V. Atividades Lúdicas na Educação. 4. Ed. Petrópolis, RJ: Vozes, 2008. 
FELIX, R. A. Z. Coleta seletiva em ambiente escolar. Rev. eletrônica Mestr. Educ. Ambient, v.18, 2007.

FILHO, J. R. O. Motivação dos alunos em sala de aula. Disponível em:

$<$ http://www.webartigos.com/artigos/motivacao-dos-alunos-em-sala-de-aula/20719/> Acessado em 7 de fevereiro de 2013.

FREIRE, P. Pedagogia do oprimido. 32.ed. Rio de Janeiro: Paz e Terra, 2002. LOUREIRO, C.F.B., LAYRARGUES, P.P., CASTRO, R. DE S. Educação ambiental: repensando o espaço da cidadania. São Paulo: Cortez, 2002.

LÜDKE, M.; ANDRÉ, M.E.D.A. Pesquisa em Educação: Abordagens Qualitativas. São Paulo: EPU, 1986.

NOGUEIRA, E. C.; SANTOS, J.; ARAÚJO, M.; FORNAZIERO, R. M.; PINTO, S. S.; MIGUEZ, S. C.; REIS, V. P.; MANGIALARDO V. C. Projeto de educação ambiental: Reciclar brincando. XV INIC / XI EPG / V INIC Jr. 2008.

OLIVEIRA, R. F. M.; PAES, L. S. Atividades didáticas para o estudo dos vegetais e o meio ambiente no ensino fundamental. Revista ARETÉ - Revista Amazônica de Ensino de Ciências, v. 2 (3), 2009.

PASSOS, C. O.; CHAVES, M. W.; COSTA, E. M. S. A Formação de um "Novo" Tipo de Professor no Modelo Nacional-Desenvolvimentista. R. bras. Est. Pedag. Brasilia, v. 75, p. 301-371, 1994.

PNLD - Programa Nacional do Livro Didático (2011). Disponível em:

$<$ http://portal.mec.gov.br/index.php?option=com_content $\&$ view=article \&id=12389\&Ite

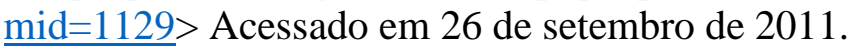

